\title{
APPLICATION OF LASERS
}

$A^{\mathrm{N}}$ informal conference on seientific and industrial applications of lasers was held at the National Physical Laboratory, Teddington, during April 23-24. Three hundred people (the maximum number it was possible to accommodate) attended, of whom twenty were from overseas.

The first day was concerned with gas lasers. During the morning, papers were presented on a variety of applications, including metrology, geodesy, communications, optical testing and alignment, navigation and machine tool control, and these and other topics were discussed during the afternoon session. The laser, as one speaker put it. is a solution in search of a problem. At present it is mainly useful in science, and there are fow applications earning money, but many where it is a very convenient light source. It was generally agreed that for broad-band communications a firther decade of component developmont is needed, and even then millimetre wave-guide communications systems may be preferable. For many other applications such as optical testing the greater convenience of the gas laser as a light source must be balanced against its greater cost. In machine tool control the laser is capable of quite unnecessarily high accuracy, but requires rigorous and expensive control of machine operating conditions. The stability of existing continuous wave gas lasers could profitably be improved, but otherwise they seem to be satisfactory. The pulsed gas laser holds promise for micro-machining of thin films.

After tea, some of the laser work in the Light and Standards Divisions of the National Physical Laboratory was displayed, and a number of commercial gas and solidstate lasers, mostly British, were demonstrated by the makors.

The second day was spent discussing pulsed solid-state lasers, the principal characteristic of which is their ability to compress energy in time, space and frequency. A paper on the applications of neodymium-doped glass lasers to machining, welding, the spectral microprobe and computers was followed by papers dealing with diode lasers, micromachining, atmospheric studies, satellite tracking, beam-riding guidance systems, electron emission from laser-heated surfaces, goneration of submillimetro waves, range-finding and ophthalmic surgery. For metal cutting operations the laser, though energetically ineffici- ent, is in competition with the electron beam machine, which can work only in a vacuum. One speaker found that ease of cutting depended on the thermal conductivity of the material, while another found that the reflectivity and binding energy were the important parameters. The laser may find application in dentistry for the selective vaporization of caries in teeth, and in surgery for drilling thin bone. It is already in successful use for anchoring detached retinæ. Tungston surfaces receiving a focused laser beam produce high-density electron emission, and may be useful as the cathodes of millimetre wave valvos. Range-finders using gallium arsenide diode lasers and ruby lasers were described, with ranges of the order of a mile and accuracy of 1 in $10^{4}$ : the diode laser hes the advantages of ease of modulution, compactness and high pulse repetition rate.

During the second afternoon discussion session many people wanted to know more about neodymium glass lasers. This material has the great advantage over crystalline materials that it can be produced in large optically homogeneous blocks with quite high neodymium concentrations. In pulsed operation with water cooling, a pulse repetition frequency of one a second has been achieved, but the cost goes up more than proportionally to the repetition rate. The surface damage observed at high pumping power densities can be avoided by cladding the neodymium glass with a plain glass, and solarization is prevented by filtering out ultra-violet radiation. The difficulty of obtaining laser pulses longer than $1 / 100$ sec, desirable for welding applications, was emphasized. On the question of range-finder accuracy, improved narrow-band filters for the detector would be helpful, though thermal drift of the transmitter wave-length would have to be considered.

Many applications had to be left out, or received only cursory attention, including high-speed photography, plasma physics, vision in fog, testing of optical components and education in optics.

Commercially, perhaps, the picture presented was disappointing, at least in the short run. Much development remains to be done before many industrial applications become possible. It is still true that the principal applications of the laser are in scientific work, where it is invaluable.

T. P. HUGHFS

\section{ORDER-DISORDER STRUCTURES}

A SYMPOSIUM on order-disorder structures was held under tho auspices of the Slovak Academy of Science and the German Academy of Sciences in Berlin at Castle Smolenice, near Bratislava, during May 19-23. There were some sixty participants from six countries, namely, Czechoslovakia, German Democratic Republic, Hungary, Japan, the United Kingdom, and the U.S.S.R. The symposium was organized by Prof. K. Dornberger-Schiff (Berlin) and Dr. F. Hanic (Institute of Inorganic Chemistry, Slovak Academy of Science).

Prof. Dormberger-Schiff gave a review of the subject, which in its present stage of development owes very much to her and to colleagues in Adlershof. A foundation has been given to the systematic theory of the symmetry operations which are involved in the separato layers, and in their mutual arrangements, in a large class of orderdisorder structures. The application of these conceptions to the solution of the structure of strontium germanate was very striking. Prof. B. B. Zvjagin (U.S.S.R.) proposed a classification of layer silicates and Dr. V. A.
Dritz (U.S.S.R.) discussed the imperfections in lizardite. The silicates were also the subject of a report by Dr. J. A. Gard (United Kingdom), in which he described the application of electron diffraction to these investigations. Dr. W. A. Wooster (United Kingdom) described the application of automatic photographic and diffractometric methods to the study of diffuse reflexions of all kinds.

A group of papers dealing with problems of disordor of a more general kind was presonted by several spealkers. Prof. G. S. Zhdanov (U.S.S.R.) spoke about crystals showing a combination of Seignotte-electric properties with ferro- or anti-ferro-magnetic properties. Dr. L. Zsoldos (Hungary) dealt with a now approach to the problem of the disorder shown by $\mathrm{Cu}_{3} \mathrm{Au}$. Dr. K. Doi (Japan) gave an analysis which permits of a direct determination of atomic displacements in disordered alloys. Prof. A. J. C. Wilson (United Kingdom) described the use of variance as a measure of line broadening and its use in the study of stacking faults. 
Castle Smolenice is situated at the foot of the Lower Carpathian mountains and is in a beautiful countryside. It now provides both a holiday resort and a meeting-place for scientists and is maintained by the Slovak Academy of
Science. Apart from the scientific programme there was a well-arranged ladies programme and an excursion to Bratislava for all members of the Symposium.

W. A. WoOster

\section{BRITISH LEATHER MANUFACTURERS' RESEARCH ASSOCIATION}

$\mathrm{D}^{\mathrm{u}}$ URING the open days at the Egham Laboratories of the British Leather Manufacturers' Research Association, which were held during May 12-14, members of the staff gave short lectures on subjects of particular interest.

1)r. J. H. Bowes spoke about hides from intensive feeding trials and other accelerated stock-raising methods; in composition and loather-making characteristics they resemble the lighter hides from normally fed animals of the same age. In the hair-loosening process, one of the most critical stages of leather manufacturing, alkaline unhairing treatments loosen the keratin structure by breaking its disulphide links while enzyme methods mostly act by dissolving non-keratinous protein around the hair bulb so that the hair can be pulled from the follicle. These procedures are being re-examined by the Biology and Biochemistry Departments, one object being to diminish the effluent problem caused by waste unhairing liquors.

Other work arising from effluent problems was described by Dr. R. G. Mitton, who described the complete utilization of vegetable tanning liquors with no discharge of wastes and by Mr. D. A. Bailey, who dealt with ehlorination and aeration of waste sulphide liquors. In addition to work on offluent problems the Chemical Engineering Department continues its investigations into drying leather. The efficiency (in heat and power) of vacuum drying has been examined and was described by Dr. F. E. Humphreys.

In the A.ssociation's first quarter-century, the research programme was mainly occupied with investigations of leather-making processes; but more attention is directed nowadays to finishing processes and to the properties of leather which are important to users. Mr. T. J. Bickerton outlined the problems met with in dyeing (many of which are due to resistance to wetting in areas whero fatty compounds persist from the original skin), and Mr. A. W. Landmann discussed the new methods of applying pigmented finishes (in particular the mechanized 'curtaincoating', which has been adopted from the timberfinishing industry). Miss B. M. Haines spoke on adhesives for leather and the preparation of leather for cementing, a very important subject in many uses of leather. It is for example, essential that adhesives used in suède and grain leather garments shall be resistant to dry-cleaning solvents.

In the Chemistry Department, the display of work on the organic chemistry of tannins dealt with the reactivity of $3: 4$ diol flavonoid compounds. from natural sources or synthetic. The Physies Department showed new tests which are being developed for various properties of leather, and the continuation of work on waterproofing and heatsetting (moulding to shape) of upper and elothing leather. Dr. J. H. Bowes spoke on the recently completed project (sponsored by the U.S. Department of Agriculture) on the resistance of leather to de-tanning treatments and the chemical stability of collagen and leather fibres. A new contract has bcen awarded by the Department of A.grieulture for work in the Biochemistry Department on compounds which react chomically with collagen and can be used to improve the characteristics of leather.

M. P. B $\triangle \triangle L F E$

\section{FLAME-RESISTANT RUBBERIZED HAIR}

$\mathrm{F}^{-1}$ OR many year's natural rubber latex has boen used for bonding fibres together in various forms to produce packaging and particularly upholstery filling materials. Curled animal hair is most commonly used for this purpose, the popular material being hog hair blended with small proportions of longer hajr derived from cattle tails, horse tails and manes. For packaging. at least 80 per cont hog hair is normally specified. Alternatively, certain vegetable fibres, such as coir (coconut fibre), used alone or blended with sisal, are suitable for some applications. The function of the latex as bonding agent is to improve load-carrying capacity, resilience and resistance to compression. For domestic upholstery and private transport, in conjunetion with springs, these rubberized materials have withstood the test of time; latterly their use has found favour for packaging radio and electronic instruments and other fragile equipment.

According to E. G. Pole, in an article in Rubber Develop ments (quarterly journal of the Natural Rubber Producers' Research Association, Malayan Rubber Fund Board, 17. No. 1; 1964): "It has been suggestod that usage could be further expanded into new and virtually untapped markets, such as that of public transport seating, if only flame-resistant properties could be added to the already excollent physical properties of natural rubber bonded hair pads".
The use of certain combustion retarding materials. for example, ammonium salts borates, metallic oxides. chlorinated hydrocarbons, with natural rubber latex. has boon recognized for somo years past. but high lovels of these compounds are required and it has been found that the elastic properties of the products involved in this treatment are adversely affected. Natural rubber can now be modified chemically to give more permanent Hame-resistant properties without impairing the elastomeric characteristics of rubber latex by reacting it with polyhalogenated compounds in the presence of suitable catalysts. Trichlorobromomethane is the preferred compound and it is stated: "The reaction ... proceeds nearly to completion at room temperaturo and can thus bo regarded as a maturation or coinpounding stop in the preparation of a latex compound suitable for the production of flame-resistant rubberized hair".

It has been found that the optimum combination of flame-resistance and good physical properties in the modified rubber is obtained when latex is compounded with between 14 and 20 parts by weight of trichlorobromomethane per 100 parts by weight of rubber.

The article gives both recipe and procedure for production of rubberized hair with good flame-resistant properties. together with relevant illustrations and appropriate references. 